\title{
Pay Transparency and Labor Market Justice
}

\author{
Daniel Halliday (D), Associate Professor in Political Philosophy, Historical, and Philosophical Studies
}

University of Melbourne, Victoria, Australia

\begin{abstract}
I argue that a general initial case for pay transparency can be made given the role played by transparency of information about prices in bringing markets closer to the ideal of competition or equilibrium price. This initial case might then be limited or enhanced depending on more specific considerations about the status of information about pay in particular. Privacy considerations seem to count against pay transparency, but I argue here that the context of pay information lacks some features present in other contexts in which appeals to privacy have force. Building on work by Estlund, Moriarty, Caulfield, and others, I argue that pay transparency may be favoured by considerations relating to personal autonomy in labour markets. Finally, I argue that pay transparency may contribute towards the realization of conditions of publicity, particularly relating to the value of citizens' assurance about each other's tax compliance.
\end{abstract}

Keywords - pay transparency, labor markets, privacy, autonomy, publicity

Acknowledgments: I thank the organizers and other participants at the conference 'Using Transparency to Achieve Equality', held at Melbourne Law School in 2020, for feedback on earlier versions of this paper. In addition, I thank John Thrasher, along with two anonymous referees for Law in Context, whose input led to improvements on an earlier manuscript.

Disclosure statement: No potential conflict of interest was reported by the author.

License: This work is under Attribution-NonCommercial-ShareAlike 4.0 International (CC BY-NC-SA 4.0)

https://creativecommons.org/licenses/by-nc-sa/4.0/

Suggested citation: Halliday, D. (2021). “Pay Transparency and Labor Market Justice.” Law in Context, 37 (2): 27-36, DOI:

https://doi.org/10.26826/law-in-context.v37i2.147

\section{Summary}

1. Introduction

2. Transparency and ideal markets

3. The significance of privacy

4. Strengthening the case for pay transparency

4.1. The argument from autonomy

4.2. The argument from publicity

5. References

\section{INTRODUCTION}

Should we be able to discover what others at our own workplace earn? What about finding out what our nextdoor neighbor, or even a total stranger, gets paid?
Would a society that pursued greater levels of pay transparency be, in any respect, a more just society? This paper considers some answers to these questions. 
Numerous jurisdictions have included pay transparency in their regulation of employment. Many countries have promoted a weak degree of transparency by prohibiting firms from practicing strong forms of pay secrecy, that is, to forbid employees from talking about their pay. Anti-secrecy rules need not be accompanied by any stronger requirement that employers make information about pay especially public. Among the jurisdictions with stronger transparency requirements, the Norwegian tax office has made it possible to download the full tax returns of individual citizens. This allows information to be found not just about an individual's pay, but about a range of other aspects of their financial affairs.

These differences at the level of policy reflect the fact that transparency itself is somewhat multi-dimensional. One dimension concerns its range: pay details may be released within individual firms and be common knowledge among employees, but without being made public outside the firm. Or transparency can apply to the entire labor market, with everyone's pay information accessible to all fellow citizens, perhaps by way of some central database as in Norway. Another dimension pertains to its specificity, or the degree of personal information disclosed. A firm, for example, might publish its entire pay scale but not identify which individuals are at which level of the scale, or even how many individuals are at each level. Or transparency may only go so far as to reveal certain types of group-membership, such as gender, preserving anonymity of individuals. Most jurisdictions practice some degree of non-individualized transparency through government institutions like national offices of statistics, which publish data about the median wage and other aspects of the distribution of earnings. There are often rules requiring corporations to disclose the pay of their top executives in order to sell shares on the stock market. Alongside state institutions, some private-sector agencies collect and publicize data online, including salary data, largely for free. Familiar examples include websites like Glassdoor, where workers can volunteer information about their pay levels (among other things). While perhaps harder for government to control, it remains a matter of public policy as to how these websites are permitted to operate. Such complexity makes it harder to reach very straightforward conclusions about whether transparency is overall something that might promote justice in labor markets - it depends on what kind of transparency we're talking about, as well as how much of that kind. One way, nonetheless, to approach the question is to ask, in an ideally just society, how much pay transparency there would be, and what kind(s). Much academic study of pay transparency does not seek to pursue exactly this question. That is to say, existing discussion of transparency typically does not ask whether transparency is itself a requirement of justice. Legal scholars have discussed the potential of transparency to improve employer compliance with anti-discrimination legislation, or perhaps work against other unjust inequalities, such as a gender pay gap, beyond the extent to which such inequalities violate legal requirements. ${ }^{1}$ Here, transparency is a means to securing a higher level of justice in a labor market, but not necessarily an essential means: There might be nothing wrong with these requirements being satisfied through mechanisms that are compatible with low levels of pay transparency. Another common approach, such as that taken in management studies, examines the impact of pay transparency on such things as worker motivation and morale, or other aspects of workplace culture. While significant, these questions are more tenuously connected with issues of labor market justice. ${ }^{2}$

Alongside the larger bodies of work in legal and management studies, a philosophical and legal literature has begun to emerge, appraising arguments for and against pay transparency as a requirement of labor market justice in its own right. This paper is an attempt to contribute to these efforts.

\section{TRANSPARENCY AND IDEAL MARKETS}

I am going to take the general burden of justification as being in favor of pay transparency rather than against

\footnotetext{
${ }^{1}$ For example Ramachandran (2012); Reilly (2019).

${ }^{2}$ This is not to say that workplace culture lacks moral significance. For extensive discussion see Singer (2019).
} 
it. This stems from a view implicit in contemporary political philosophy about the general evaluation of market order, including labor markets. It is fair to say that different conceptions of justice, such as libertarianism, egalitarianism, utilitarianism (and their variants) embody different normative perspectives on market order. But it is nowadays unusual to find a serious conception of justice that rejects market order outright. ${ }^{3}$ Contemporary theories of justice really offer different perspectives on how markets should be enabled, constrained, or modified in various ways. Some of these disagreements are about the scope of market order, being focused on whether some goods and services should not be supplied wholly by markets. Egalitarians and libertarians tend to disagree, for example, on whether the state should raise taxes to fund the production of education, healthcare, and other services made free at the point of consumption, or whether these should all be left entirely to the market. Other disagreements have to do with what justice might require by way of modifying the distribution of wealth or resources that market order brings about. Again, the main disagreements are compatible with the idea that market order is perfectly appropriate in principle, including markets in labor. ${ }^{4}$

Disagreements about justice, then, take it for granted that goods and services are largely produced and distributed by markets, including markets in human labor. But it is important to note that the appropriateness of markets depends largely on to the extent that they are competitive. Broadly speaking, this happens when the prices at which goods and services are sold reflects a process whereby supply has been allowed to meet demand, and the market exhibits an 'equilibrium price'. If markets are not competitive and transactions occur at non-equilibrium prices, then one party in the transaction is benefitting from whatever factor is preventing equilibrium price from being reached. Such factors are many and varied. Familiar categories include barriers to entry, monopoly, and asymmetry of information, each of which distort prices. None of this is to say that the ideal of competitive price is all there is to what justice requires of markets (the persistence of disagreements like those mentioned above is evidence of this). But it may be that many objections to status quo market order have to do with ways in which actual markets fail to meet the ideal of competition, which is usually true of real markets. ${ }^{5}$ At any rate a plausible view is that when prices are uncompetitive, some justification is required for not seeking regulation that might correct this.

What does this have to do with pay transparency? Markets tend to become more competitive when they are subject to transparency as to what transactions are occurring at what price. The prospects for an equilibrium price being reached are enhanced when participants can see what other transactions are occurring and modify their behavior accordingly. If the price of any item in a grocery store is competitive, this is partly because consumers have been able to use information about prices to choose which store to use, and because stores themselves (and their suppliers) use the same information to compete on price. This would not happen without transparency: Imagine a scenario in which grocery stores kept the prices of canned tomatoes secret, only revealing a price to individual consumers when cans were brought to the checkout. Consumers would not know what other consumers had been asked to pay, and other grocery stores would not be in a position to compete on a price they couldn't see. This helps explain why price transparency is important in many markets.

It might seem that the imagined case of opaque prices in grocery stores is much like that of a labor market without pay transparency. Absent good reasons for distinguishing these two kinds of markets, there may be a strong case for requiring pay transparency in labor markets. But there may be such reasons to distinguish

\footnotetext{
${ }^{3}$ There are some exceptions within egalitarian views. For example, that markets depend on 'greed and fear', in ways incompatible with certain requirements of community and thereby equality - Cohen (2001).

${ }^{4}$ Exceptions are made for such things as child labour, and for labour where there is a moral objection to something being provided for money rather than voluntarily. For discussion of such cases see Satz (2010).

${ }^{5}$ For a fuller statement of a view of this sort, see Heath (2014, pp. 34-37).
} 
these markets. First, it is not obvious that achieving an equilibrium price for labor is important in the way that it is for the prices of more everyday goods. One point made in the philosophical literature on exploitation is that a competitive price for labor might actually mean people being paid at levels that are, for independent moral reasons, too low to be justified. 6 Any specific attempt to articulate this claim will be controversial, but the general point is that an equilibrium price for labor is not guaranteed to coincide with what's required by any plausible account of a fair price for labor. (This observation is unlikely to count in favor of allowing firms to keep pay secret, since it is doubtful that pay secrecy would make the price of labor uncompetitive in ways that also made it conform to any independent criterion of a fair price.) More generally, the morality of pay levels depends on considerations other than making the price competitive. Some of these considerations might count further in favor of pay transparency while others might count against it. The way forward is to identify and try to process what some of these considerations might be.

\section{THE SIGNIFICANCE OF PRIVACY}

If pay transparency requires overriding the privacy of individuals, then it might be unjust regardless of its impact on the competitiveness of labor markets. We might indeed feel that our earnings are nobody else's business, and a much more personal matter than the price at which we purchase supermarket goods. It is not obvious whether this intuition can be vindicated. Social norms governing conversation about personal finances are, upon close inspection, subject to some rather arbitrary distinctions that cast doubt on their moral force. It is certainly rude to directly ask how much someone earns or just to announce one's own salary as a way of keeping civil conversation going. But it is perfectly polite to ask where someone plans to go on holiday, or what car they own, even though these are quite good indicators of someone's income (or wealth) and are a way of discov- ering details of someone's personal life. Similar norms apply to actual demonstrations of one's purchasing power. It is often appropriate to spend a decent amount of money on a gift for someone. It is, however, considered uncouth to leave a price tag on a gift as a way of signaling one's expenditure. The market has found a solution: plenty of gift-app products are carefully designed so that the recipient can be assured that they cost a certain amount without the numerical price being visible. For example, the appearance of 'limited edition' on a bottle of whisky, and its presentation in a hinged wooden case are more a guarantee of a high price than of a superior taste. I offer these examples because they suggest that it is unclear exactly what should be considered private and what counts as undue intrusion or disrespect when it comes to personal financial information becoming public. Our intuitions about where the moral boundaries lie are probably rather arbitrary.

At any rate, it has proven difficult to get to the bottom of what privacy really is, when understood as a moral concept playing some role within any theory of justice. ${ }^{7}$ One possibility is to treat privacy as a proxy for some sort of entitlement not to have a specific vulnerability exposed, or to have control over how we present ourselves to others. ${ }^{8}$ One example where secrecy is important is the case of free elections. Voting should involve a secret ballot where people's voting choices remain unknown, even when individual voters remain free to disclose them. Another important example might be found in criminal justice contexts, where victims of crimes have their identity concealed from public view, or even in some cases from a jury, even after a trial has been completed. The precise strength of anonymity requirements in such cases is itself up for debate. ${ }^{9}$ It is clear, though, that both secret ballots and victim anonymity gain their justification from their role in allowing the relevant institutions to work properly. If people could not vote in secret, then elections might be open to distortion through intimidation. If victims of violent

\footnotetext{
${ }^{6}$ Sample (2003, p. 23-26).

${ }^{7}$ For a philosophical overview of privacy and its moral significance, see Lever (2012).

${ }^{8}$ The latter of these two formulations is defended at length by Marmour (2015).

${ }^{9}$ One objection to secret ballots is that they encourage selfish voting behavior - see Brennan and Pettit (1990).
} 
crimes could not avoid exposing themselves to public attention in the event of a trial, then serious crimes might go unreported. Other examples of secrecy or confidentiality may have similar justifications. The ability to make protected disclosures, for example revealing one's role in a crime to a social worker or medical doctor, might be necessary for such practitioners to give the kind of assistance it is their job to provide. What unites these cases (or at least some of them) is that any requirement of transparency will have an inhibitory effect on some independently valuable process or institution, and likely one that includes unfair burdens on certain parties involved. One might say that the function of privacy here is actually to promote greater transparency where it is truly needed, such as within the workings of a criminal investigation and trial. It is not obvious that a requirement to disclose pay will have any sort of overall inhibitory effect on labor markets. It is even less obvious that any such effect would be one especially burdensome for individual people who have distinctive vulnerabilities.

Overall, I don't think there is a strong case against pay transparency that can be derived from privacy. ${ }^{10}$ Cases I have described in which privacy does count in favor of some kind of secrecy protection seem to share features that set them collectively apart from the case of transparency about pay. That being said, if there's one very general argument against pay transparency on privacy grounds, it may be that transparency of this sort arbitrarily privileges one aspect of a person's financial affairs. People who rely on income from labor (which is most people) may have a legitimate complaint if their pay is disclosed while people who rely on other kinds of income, for example from capital or other wealth holdings, are under no such requirement. Why should personal wealth be a private matter, but personal income (from labor) not be? Of course, the answer might appeal to differences in the causal roles of making these different facts transparent: While pay transparency may have a valuable effect in quelling forms of discrimination in labor markets, it is not immediately obvious how transparency about personal wealth would have such effects. I shall later argue that the right response to this point might be to seek transparency with regard to a wider range of personal financial matters of citizens.

\section{STRENGTHENING THE CASE FOR TRANSPAR- ENCY}

\subsection{THE ARGUMENT FROM AUTONOMY}

In separate writings, Jeffrey Moriarty and Cynthia Estlund have argued that pay transparency may be a requirement of justice due to its capacity to enhance the autonomy of workers making choices about how to navigate labor markets. For Moriarty, this is mainly a matter of transparency at the point of deciding whether to seek a particular job: "Knowing how much people get paid for performing certain sorts of jobs will help [a person] to decide which jobs to pursue." 11 This includes not just the prospect of choosing between which industries to try and enter, as might be the task faced by a graduating university student, but also whether to try and move firms within a particular industry.

Certainly, individuals are in a better position to navigate labor markets, and to pursue jobs that best fit their life goals, the more knowledge they have about which jobs pay which amounts. It can be annoying to see a job advertisement that merely reports 'competitive salary' without saying what the salary actually is. Overall, the place of individual autonomy as an important value is well-established in moral and political philosophy, and any doubts about how to best interpret it probably don't attach to how it might be promoted by greater pay transparency. The harder question is exactly what type or degree of transparency might be required.

It is one thing for a university graduate to be given transparency as to the starting salary of an employer seeking to recruit them. But a starting salary is just that. A prospective employee's autonomy would also be enhanced by knowledge of other facts about pay, such as

\footnotetext{
${ }^{10}$ One point I do not rely on, but which may count against a privacy-based case for pay secrecy, is that the personal preference for keeping one's earning secret appears to vary with birth cohorts. See Estlund (2014, p. 797).

${ }^{11}$ Moriarty (2018, pp. 692-693). For Estlund's position see her (2014, p. 788).
} 
facts about frequency of promotion, prospects for remuneration above base salary (such as bonuses and in-kind benefits), and so on. So, if autonomy is what matters, then there is a case for requiring that information of each sort, and perhaps others, be made public by employers. What's less obvious is whether such information should convey anything about the identities or demographic characteristics of who is at which pay level. Disclosure of demographic information may sometimes enhance the autonomy of members of the relevant group. For example, if a firm tends not to promote women, transparency about this would enable women employees to see that they have reason to move to a different firm, and prospective women employees that they have reason to not seek employment there. One reason for being cautious is that certain kinds of information could promote a negative feedback loop. If it becomes known that a firm is bad at promoting women, this may make it harder for that firm to improve its performance if it finds that women employees leave and women won't join. It is up for debate as to how bad such an outcome would be: Labor market justice does not actually require that any particular firm improves, only that labor markets improve overall. Justice may be neutral between poor-performing employers becoming more justice-compliant, and them going out of business (or incurring reduced market share) and being replaced by more justice-compliant competitors. That being said, autonomy in labor markets probably doesn't require knowing what specific individuals earn. At any rate, neither Estlund nor Moriarty argue for why pay transparency should go quite this far.

It bears emphasizing that labor market participation is characterized both by a relatively low frequency of transactions relative to other markets, and the consequences of agreeing to a particular transaction (i.e., accepting a job) being high relative to most other transactions of any frequency. To make this more vivid, consider again the comparison with shopping for canned tomatoes or any other frequently purchased grocery item. The financial consequences of being paid less than the market price for a job are much larger, in sheer monetary terms, than paying over the odds for a single grocery item, even if one ends up doing this repeatedly. Moreover, the selection of a job also impacts on one's life with respect to a range of non-monetary benefits and burdens of performing the work in question, typically much more so than grocery shopping. ${ }^{12}$ All of this is compounded by the fact that the effects of accepting employment often last for years, and that there are costs to switching jobs that typically do not apply when it comes to changing the transactions one makes in other markets. I make these points just to reinforce the plausibility of the argument from autonomy.

Again, though, we might think that labor markets are importantly special, relative to many other markets. A point worth emphasizing here is the fact that what one is paid reflects one's own specific sets of skills and capabilities. People are not standardized in the way canned tomatoes are. Our sense of this might be part of what makes the appeal to privacy, discussed earlier, rather intuitive. But the fact that people differ when it comes to the kind of labor they might be able to sell may be a reason against transparency in ways that aren't actually about privacy at all. To put it bluntly, the fact that people are not 'standardized' means that what their labor is worth may be something that needs to be 'discovered' by way of some negotiation process, terminating in a particular set of terms under which the labor is sold. Transparency might work against this.

Canned tomatoes can reach an equilibrium price in part because what's at stake when they are bought and sold is largely constant: Selecting a can of tomatoes is rarely a life-changing choice. Different people generally want the same thing from a can of tomatoes, there is not much variation in quality anyway, and most transactions are basically alike in terms of how the parties are situated. Thus, there is a sense in which everyone can know what the next can of tomatoes is worth just by relying on the history of canned tomato sales. Labor markets are among the markets where there can be very high variation between the various instances in which the same general type of good or service is sold, both in

\footnotetext{
${ }^{12}$ For an important development of this observation see Gheaus and Herzog (2016).
} 
terms of what is actually on offer and how it meets the needs of the purchasing party. In this respect labor markets are more like housing markets and car markets than everyday grocery shopping. ${ }^{13}$ Because transacting parties don't know in advance exactly what they want or what they might be getting, they have to negotiate so as to determine what is being sold and how much is being paid for it. Admittedly this is not true of all labor markets, particularly for unskilled work. In many cases a salary is simply offered and then either accepted or declined by the applicant. But negotiation is more common for skilled labor markets and is sometimes the norm. Pay secrecy may be an important element of what enables the negotiation process to occur.

A position of this sort is defended by Matthew Caulfield, who argues that employers might benefit from pay secrecy protections in the event of negotiating with new employees about salary. The idea here is that employers may want to bargain without having to disclose their reservation price. Pay transparency requirements, however, require them to do this. As Caulfield says, however, "we can consistently claim that an employer would greatly benefit an employee's autonomy in disclosing her reservation price in a pay negotiation, and say that it is almost certain that an employer has no affirmative duty to do so".14 One way to reinforce Caulfield's point is to consider whether prospective employees have a similar right to protect their bargaining power through secrecy. A good example of this would be an employee's right to conceal their past salaries. ${ }^{15}$ If an employer asks job applicants to disclose past (or indeed current) salary, then they gain an insight into what an applicant's reserve price might be (though perhaps other things too). But it would seem that the point here cuts both ways: If bargaining about salary is the sort of thing where participants have an entitlement to keep their reserve price secret, then that seems to count against pay transparency. If all pay were transparent, then both employers and job candidates could more easily gain an impression of each other's reserve prices.

It is true that negotiation in a range of contexts is such that parties may have some right to not disclose their reserve price. People who show up to an auction don't need to declare the maximum they would pay for an item, nor do sellers need to declare in advance the minimum they would accept. The broad justification for this is that the market is there to decide what the true value of the exchange is, and such disclosures would disrupt this. I suspect that such a case might be made for secrecy in industries where salary negotiation is especially important. And by 'important', I mean that the industry in question would work less efficiently, or be subject to some distinctive problem, were negotiation constrained in some way. The mere fact that some industries involve a lot of salary negotiation is not necessarily evidence that the industry works more efficiently because of this. Indeed, there is evidence that some markets exhibit considerable negotiation variance, which is to say that negotiation introduces something of a randomizing element,or is subject to its own set of influencing factors (for example, triggering employer biases) that cast doubt on whether it tends towards the 'discovery' of an equilibrium price. ${ }^{16}$

Overall, I think the argument from autonomy is quite strong, though it may stand in need of qualification: I have suggested that it is a stretch to appeal to autonomy in defense of transparency at the level of individual earners: Some sort of transparency up to the level of demographic difference probably yields as much autonomy benefit to individuals' labor market choices as does any stronger transparency requirement. It is also worth considering whether this much information is already available thanks to the various private-sector online services that already exist. ${ }^{17}$

\footnotetext{
${ }^{13}$ I owe this comparison, and the general point about negotiation, to Hollander-Blumoff and Bodie (2021).

${ }^{14}$ Caulfield (2020, p. 12).

15 For defense of this claim see Lobel (2020).

${ }^{16} \mathrm{Or}$ as Hollander-Blumoff and Bodie summarize this point: "Given the same negotiation problem to a variety of different individuals produces an array of vastly different results... [such that] one might speak more accurately of a market "array" than a market price" (2021, p. 1272).

17 This seems to be Caulfield's view, referring to "the wealth of information already available" (2020, p. 11).
} 


\subsection{THE ARGUMENT FROM PUBLICITY}

Transparency requirements can cause the distribution of incomes to change in certain ways. But they also allow for it to be more widely known that the distribution of income currently is a certain way. This fact might bolster the case for pay transparency, setting aside the question of whether it brings wages closer to an equilibrium price or serves any other requirement about what the distribution of incomes should look like.

The idea here is that there is moral value in there being a wide level of assurance that the requirements of justice are complied with, or at least an easy way of knowing when they are not. In slogan form, the idea is often represented as 'for justice to be done, it must be seen to be done'.18 In political philosophy this idea is typically known as a 'publicity' requirement. Publicity presupposes transparency, but is more demanding: Not only is the relevant information not kept secret, it is also disseminated in ways that make it somewhat common knowledge. The moral value of this dissemination is in securing a way in which members of society have greater assurance that their fellow citizens are complying with the rules. ${ }^{19}$

Publicity requirements are open to qualification, for example by the sorts of considerations that uphold privacy in contexts like criminal justice and voting processes. But if (as I have argued) such concerns do not vindicate any intuitions about privacy of incomes, then publicity could have some purchase here. The crucial point that needs to be first established, though, is that pay transparency would actually serve to confirm that some requirement of justice had been fulfilled. Information that does not provide assurance of some specific sort of compliance with a requirement of justice is not the sort of information that people have an entitlement to receive as part of a publicity requirement, even if there is no countervailing moral reason in favor of secrecy. Publicity requirements, in other words, depend on the presence of some prior requirement of justice whose satisfaction is conveyed in the information concerned.

A quick way to formulate a publicity-grounded case for pay transparency would be to argue that justice requires the distribution of incomes to be a certain way and then argue that it is especially important for citizens to become aware that this distribution has come about. It is, however, difficult to mount a publicity-based case for pay transparency in this way. This is because theories of justice usually don't say what the distribution of income should look like in purely quantitative terms. Even the more demanding egalitarian views want to concede something to the idea that inequalities in income can be quite permissible when they result from appropriately free choices. ${ }^{20}$ Theories of justice might offer some specific claims, for example that CEO pay should be limited and that burdensome jobs should be better paid than non-burdensome ones. But it is hard to come up with a set of numbers that a publicity requirement could 'confirm'. On almost any theory there is some non-quantitative information that would be relevant to whether the distribution of income meets the requirements of one's preferred conception of justice, but which cannot be 'read off' the distributive profile as such.

A more indirect approach is as follows. Publicity may require pay transparency not just because pay information itself fulfils a publicity requirement, but because information about pay is an important element of larger sets of financial information indicating other types of compliance. Here, a publicity requirement might hold due to ways in which the assurance of compliance is part of what might reinforce and preserve such compliance in the future. Indeed, the value of publicity is at least partly that of keeping citizens personally invested in the rules they are following, by enabling

\footnotetext{
18 The slogan is attributed to Gordon Hewart, Lord Chief Justice in England and Wales 1922-1940.

${ }^{19}$ Publicity as an important concept within political philosophy has its origins in the work of John Rawls, see (1996, pp. 66-71). Rawls believed that satisfaction of a publicity requirement would help make a just society more 'stable', in the sense that its members would be more psychologically invested in maintaining its system of rules and institutions.

${ }^{20}$ Even current philosophical defenses of socialism concede this point, e.g. Roemer (2017, p. 306).
} 
them to regard their collective compliance as something akin to a team effort in which they can take some pride. $^{21}$ I think an effective example of such requirements would be publicity with regard to compliance with taxation. A key point here is that it may be hard to secure tax transparency without having pay transparency. It is hard to gain a sense of an individual's tax compliance without knowing their pre-tax income. This will usually provide some sense of their actual net income (if only because an individual's net income can never be lower than their pre-tax income).

All of this is compatible with certain concerns about the moral limits of tax transparency. A tax return can, after all, contain quite a large amount of information about a person's life. Considerations of privacy may allow secrecy as to certain elements of a tax return, for example information about what sort of expenses an individual made that were deductible from their pre-tax income. This would be the case when transparency as to tax deductions would reveal medical expenses or charitable donations that are quite personal, and which might trigger some of the applications of privacy that apply as protections against vulnerability mentioned earlier. But this is compatible with keeping things transparent as to how much an individual was paid by their employer. It is hard to see how the disclosure of an individual's pay actually reveals anything compromising.

Two qualifications need to be made here about my claim that pay transparency would be a legitimate and central element of tax transparency. A minor qualification is that incomes from labor are only contingently part of the tax base. While the taxing of income is now widespread in developed economies, it might not always be. A jurisdiction that restricted taxes to bases like consumption, land, inheritance and so on would not have a reason to include pay transparency as part of tax transparency. This is currently a remote possibility, even if there is some room for philosophical doubts about whether justice really requires income tax rather than other types of tax. ${ }^{22} \mathrm{~A}$ more major consideration may be that much of the need for assurance over tax compliance is over the affairs of individuals (and perhaps corporations) for whom income from labor is not a principal source of income. Arguably, the persistence of the income tax is owed to the fact that, as taxes go, it is rather hard to avoid altogether, at least when gathered by way of employer withholdings. If tax avoidance is committed largely with respect to other tax bases, then knowledge of income tax paid may seem not to provide the desired assurance. While this is to some extent true, this claim might be exaggerated. Indeed, one way on which the wealthy pursue tax avoidance is by finding ways to reduce their pre-tax income, for example by retaining control rights in property that is legally owned by other persons, such as a family foundation or other 'shell' entity. Indeed, public knowledge that an evidently wealthy individual in fact has a legally tiny pre-tax income, or at least pays very little income tax, provides evidence that some sort of tax-avoidance is going on.

The role of pay transparency in providing assurance about tax compliance may contrast with its role in confirming other types of compliance where the assurance provided merely confirms rather than actually reinforces the compliance. Assurance of tax compliance are empirically correlated with wider trust in government and indeed willingness to comply with the same rules: There is a positive feedback loop where assurance of compliance maintains ongoing compliance. ${ }^{23}$ In addition, there is the fact that tax fraud and tax avoidance ${ }^{24}$ frequently cause governments to lose substantial amounts of revenue, compared to other fiscal fraud that seems to have a worse reputation (for example, benefits fraud, which causes tiny losses by comparison). For this

\footnotetext{
${ }^{21}$ This accords with Rawls's own remarks in certain places, e.g. Rawls (1996, p. 204).

${ }^{22}$ For defense of the view that justice does require use of (progressive) income taxes, see Emerton James (2018).

${ }^{23}$ For some discussion see Bobek et al (2007).

${ }^{24}$ I take it to be plausible that both tax avoidance and tax evasion can be violations of justice.
} 
reason, drawing public attention to tax compliance may have valuable effects in shifting perspectives about which sorts of noncompliant behavior are of greatest social cost.

In sum, I think there is an interesting case for pay transparency that can be constructed out of the moral value of publicity, even though publicity likely only requires pay transparency because this would be an admissible element of a wider type of tax transparency. What might be most important, though, is that such transparency would be at the level of individuals, just because it is individuals (and not demographic groups) that pay taxes. This may be one way of beginning to vindicate the Norwegian practice.

\section{REFERENCES}

1. Bobek, D. Roberts, R. and Sweeney, T. 2007. "The Social Norms of Tax Compliance: Evidence from Australia, Singapore and the United States." Journal of Business Ethics, 74 (1): 49-64

2. Brennan, G and Pettit, P. 1990. "Unveiling the Vote." British Journal of Political Science, 20 (3): 311-333

3. Caulfield, M. 2020. "Pay Secrecy, Discrimination, and Autonomy." Journal of Business Ethics, (2020: online view)

4. Cohen, G.A. 2001. "Why Not Socialism?" in E. Broadbent (ed.) Democratic Equality: What Went Wrong? Toronto, ON, Canada: University of Toronto Press: 58-78.

5. Emerton, P. and James, K. 2018. "The Justice of the Tax Base and the Case for Income Tax" in M. Bhandari (ed.) The Philosophical Foundations of Tax Law. New York, NY, USA: Oxford University Press

6. Estlund, C. 2014. "Extending the Case for Workplace Transparency to Information About Pay."
UC Irvine Law Review, 4 (2): 781-800

7. Gheaus, A. and Herzog, L. 2016. "The Goods of Work (Other Than Money!)" Journal of Social Philosophy, 47 (1): 70-89

8. Heath, J. 2014. Morality, Competition and The Firm. New York, NY, USA: Oxford University Press

9. Hollander-Blumoff, R. and Bodie, M. 2021. "The Market as Negotiation." Notre Dame Law Review, 96 (3): 1257-1317

10. Lever, A. 2012. On Privacy. London, UK: Routledge

11. Lobel, O. 2020. "Knowledge Pays: Reversing Information Flows and the Future of Pay Equity." Columbia Law Review, 120 (3): 547-611

12. Marmour, A. 2015. "What is the Right to Privacy?" Philosophy \& Public Affairs, 43 (1): 3-26

13. Moriarty, J. 2018. “Against Pay Secrecy.” Journal of Applied Philosophy, 35 (4): 689-704.

14. Ramachandran, G. 2012. "Pay Transparency." Penn State Law Review, 116 (4): 1043-1079.

15. Rawls, J. 1996. Political Liberalism (expanded edition). New York, NY, USA: Columbia University Press.

16. Reilly, A. 2019. "Why New Zealand Employers should be subject to Mandatory Pay Transparency." Journal of the Australasian Law Academic Association, 12: 86-95.

17. Roemer, J. 2017. "Socialism Revised." Philosophy \& Public Affairs, 45 (3): 261-315.

18. Sample, R. 2003. Exploitation: What It Is and Why It's Wrong. New York, NY, USA: Rowman \& Littlefield

19. Satz, D. 2010. Why Some Things Should Not Be For Sale: The Moral Limits of Markets. New York, USA: Oxford University Press

20. Singer, A. 2019. The Form of The Firm: A Normative Political Theory of The Corporation. New York, NY, USA: Oxford University Press 